\title{
Elucidation of predictors of disease progression in patients with relapsing polychondritis at the onset: potential impact on patient monitoring
}

\author{
Jun Shimizu, Yoshihisa Yamano, Kimito Kawahata and Noboru Suzuki ${ }^{*}$ (D)
}

\begin{abstract}
Background: In patients with relapsing polychondritis (RP), organ involvement developed in those with progressive and/or long disease courses. For their management, elucidation of a subgroup suggesting disease progression is awaited.

Methods: We previously conducted a physician's questionnaire-based retrospective study to elucidate major clinical features of Japanese patients with RP. We here evaluated organ involvement at disease onset and at the last followup. We then counted cumulative numbers of involved organs at the last follow-up in 229 RP patients and compared them with involved organ numbers at disease onset, as possible indicators of disease progression. We assigned their prognosis at the last follow-up into "patient prognostic stages" from no medication (stage 1) to death (stage 5). We utilized nonparametric tests for group comparisons.

Results: Involved organ numbers per-patient were $1.13 \pm 0.03$ at disease onset and $3.25 \pm 0.10$ at the last follow-up (disease duration was $4.69 \pm 0.33$ years), and increased along with the patient prognostic stages.

At disease onset, 135 and 48 patients had auricular involvement (59\% of 229 patients, defined as auricular-onset subgroup; $\mathrm{AO}$ ) and respiratory involvement (21\%, respiratory-onset subgroup; $\mathrm{RO})$, respectively. 46 patients presented with other conditions (20\%, miscellaneous-onset subgroup; MO) including CNS, ocular, and inner ear involvement, among others.

$\mathrm{RO}$ patients showed worse (poorer) prognostic stages than $\mathrm{AO}$ patients. $\mathrm{MO}$ patients developed respiratory and/or auricular involvement thereafter and then showed significantly higher mortality rate $(15 \% ; 7 / 46)$ than AO patients (5.9\%; 8/135).

In RP patients who did not develop respiratory involvement until the last follow-up (throughout the disease course; 117 patients), mortality rate was 19\% in $26 \mathrm{MO}$ patients and 3.3\% in $91 \mathrm{AO}$ patients. Accordingly, RO patients and $\mathrm{MO}$ patients associated with relatively poor prognosis compared with $\mathrm{AO}$ patients.

(Continued on next page)
\end{abstract}

\footnotetext{
* Correspondence: n3suzuki@marianna-u.ac.jp

Department of Immunology and Medicine, and Division of Rheumatology and Allergology, Institute of Medical Science, St. Marianna University School of Medicine, Sugao 2-16-1, Miyamae-ku, Kawasaki 216-8511, Japan
}

C C The Author(s). 2020 Open Access This article is licensed under a Creative Commons Attribution 4.0 International License, which permits use, sharing, adaptation, distribution and reproduction in any medium or format, as long as you give appropriate credit to the original author(s) and the source, provide a link to the Creative Commons licence, and indicate if changes were made. The images or other third party material in this article are included in the article's Creative Commons licence, unless indicated otherwise in a credit line to the material. If material is not included in the article's Creative Commons licence and your intended use is not permitted by statutory regulation or exceeds the permitted use, you will need to obtain permission directly from the copyright holder. To view a copy of this licence, visit http://creativecommons.org/licenses/by/4.0/. The Creative Commons Public Domain Dedication waiver (http://creativecommons.org/publicdomain/zero/1.0/) applies to the data made available in this article, unless otherwise stated in a credit line to the data. 
(Continued from previous page)

Conclusions: Allocation of patients to $\mathrm{RO}$ and $\mathrm{MO}$ subgroups was suggested to associate with poorer prognosis of $\mathrm{RP}$ than AO subgroups, especially AO subgroups without respiratory involvement throughout. All RP patients deserve careful monitoring but special attention should be paid to MO patients because of their diverse and accelerated disease progression.

Keywords: Auricular involvement, CNS involvement, Relapsing polychondritis, Respiratory involvement

\section{Background}

Relapsing polychondritis (RP) is a multisystem disorder characterized by the recurrent inflammation of the cartilage, such as auricular, nasal, respiratory, valvular, and articular chondritis [1]. Other proteoglycan-rich tissues, namely eyes, heart, blood vessels, inner ears, and kidneys were frequently involved [1]. Major causes of death were reported to be respiratory complications, such as pneumonia and airway collapse [2,3]. A recent clustering analysis described that RP patients with respiratory involvement demonstrated relatively lower mortality rate than the previous studies probably because of improved management [4]. Various symptoms with several clinical clusters make it difficult to diagnose and studies now focus on the potential room of imaging technique for the diagnosis of RP [5], as well as for evaluating activity and extent of the disease.

We conducted an epidemiological survey of 239 Japanese RP patients in 2009 and collected clinical information [6]. We found a strong inverse relationship between the incidence of respiratory involvement and that of auricular involvement, suggesting that patients with respiratory involvement and patients with auricular involvement were mutually exclusive [7].

We then divided the patients into 3 subgroups, namely patients with respiratory involvement (without auricular involvement), patients with auricular involvement (without respiratory involvement), and patients with both respiratory and auricular involvement at the last follow-up [8]. Patients with both respiratory and auricular involvement suffered frequently from progressive and long disease courses. Indeed, some patients with mild diseases at the onset developed more aggressive diseases having both respiratory and auricular involvement. Predictors of disease progression are awaited for establishing better clinical management.

Here, we compared severity of RP at disease onset with that at the last follow-up to elucidate disease progression including possible termination due to death. We investigated whether one of the most significantly associated factors at disease onset with overall mortality rate served as a predictor of disease progression.

\section{Methods}

\section{A multi-institutional study survey with a subgroup analysis}

We conducted a retrospective cohort study using a physician questionnaire in Japanese major medical facilities to characterize the epidemiology, clinical features, and outcome of RP [6]. All physicians who got the questionnaire were informed the purpose of the study and their questionnaire responses would be kept confidential [6]. Onset of RP was assessed according to McAdams criteria [2]. The physicians performed tissue biopsies in 95.4\% patients. $60.5 \%$ of the patients who underwent biopsy were histologically diagnosed as having RP [6]. $52.1 \%$ of the patients were screened for the inflammation with computed tomography, magnetic resonance imaging, and/or scintigraphy [6].

The questionnaire consisted of 5 sections, namely patients' profiles, clinical features, laboratory findings, treatment, and prognosis. In the clinical feature section, physicians examined the involved organs at disease onset and at the last follow-up by assigning into 10 items, namely 1) auricular, 2) nasal, 3) inner ear, 4) joint, 5) ocular, 6) respiratory, 7) skin, 8) cardiovascular, 9) central nervous system (CNS), and 10) renal involvement. In this study, we counted cumulative numbers of involved organs, and then calculated their average (on a per-patient basis) in each subgroup. We considered them as a possible indicator of disease progression for comparison.

The prognosis was assigned into 5 items, namely 1) no medication, 2) well-controlled, 3) limited responses, 4) progressive disease courses, and 5) death. We considered such a prognostic stage value as a quantitative indicator of disease severity.

We previously found that auricular involvement and respiratory involvement were two major independent clinical features in the assessment of disease progression $[7,8]$. To characterize disease progression of RP in the current study, we evaluated the parameters (mean numbers of involved organs on a per-patient basis, prognosis stage values, and mortality rates) based on the "space", namely auricular involvement and respiratory involvement, and the "time", namely the disease onset and the last follow-up [9]. 


\section{Statistical analysis}

We utilize several nonparametric tests in this study [1012]. We compared age, disease duration, involved organ numbers, and prognostic stages using Steel-Dwass test. We compared the incidence of organ involvement using dummy variables. The values 0 and 1 indicated the absence and presence of organ involvement, respectively, and were compared by Steel-Dwass test. We compared mortality rates using chi-square and Fisher's exact tests. These parameter titers were expressed as mean \pm standard error of the mean. $P$ value less than or equal to 0.05 was considered significant. We used software JMP 13.0.0 (SAS Institute Japan, Tokyo, Japan) for statistical analysis.

\section{Results}

We conducted an epidemiological survey and obtained data of 239 RP patients in 2009 [6]. In the current study, we excluded 6 patients from the recruited 239 patients because of lack of relevant data. After preliminary analysis, we decided to exclude additional 4 patients with both auricular and respiratory involvement at disease onset to simplify the analysis. Thus, we conducted this study with total 229 patient data.

One of 229 patients was positive for myeloperoxidase antineutrophil cytoplasmic antibody with laryngeal chondritis and had no signs of systemic vasculitis. Due to the lack of symptoms of vasculitis, we included the patient in this study.
Calculation of involved organ numbers on a per-patient basis at disease onset and at the last follow-up

We counted involved organ numbers of each patient and calculated their averages in $229 \mathrm{RP}$ patients (Fig. 1). Involved organ numbers were $1.13 \pm 0.03$ organs at disease onset. At the onset, 201 patients had single manifestation and 28 patients had multiple manifestations. Cumulative numbers of involved organs were $3.25 \pm 0.10$ organs at the last follow-up. Disease duration from the first symptom to the last follow-up was $4.69 \pm 0.33$ years. These findings support that cumulative numbers of involved organs per-patient may be a possible indicator of disease progression.

Significant association of cumulative numbers of involved organs per-patient with their prognostic stages

Physicians were asked to determine prognostic stages from 5 items of prognosis in the section of the questionnaire, namely 1) no medication (11 patients, $4.8 \%$ of 229 patients), 2) well-controlled (155 patients, 68\%), 3) limited responses (32 patients, 14\%), 4) progressive disease courses (9 patients, 3.9\%), and 5) death (22 patients, 9.6\%).

We assessed the relationship between cumulative numbers of involved organs per-patient and their prognostic stages. The prognostic stages positively correlated with cumulative numbers of involved organs per-patient (Fig. 2). We found that the numbers of involved organs increased corresponding to the prognosis stages.

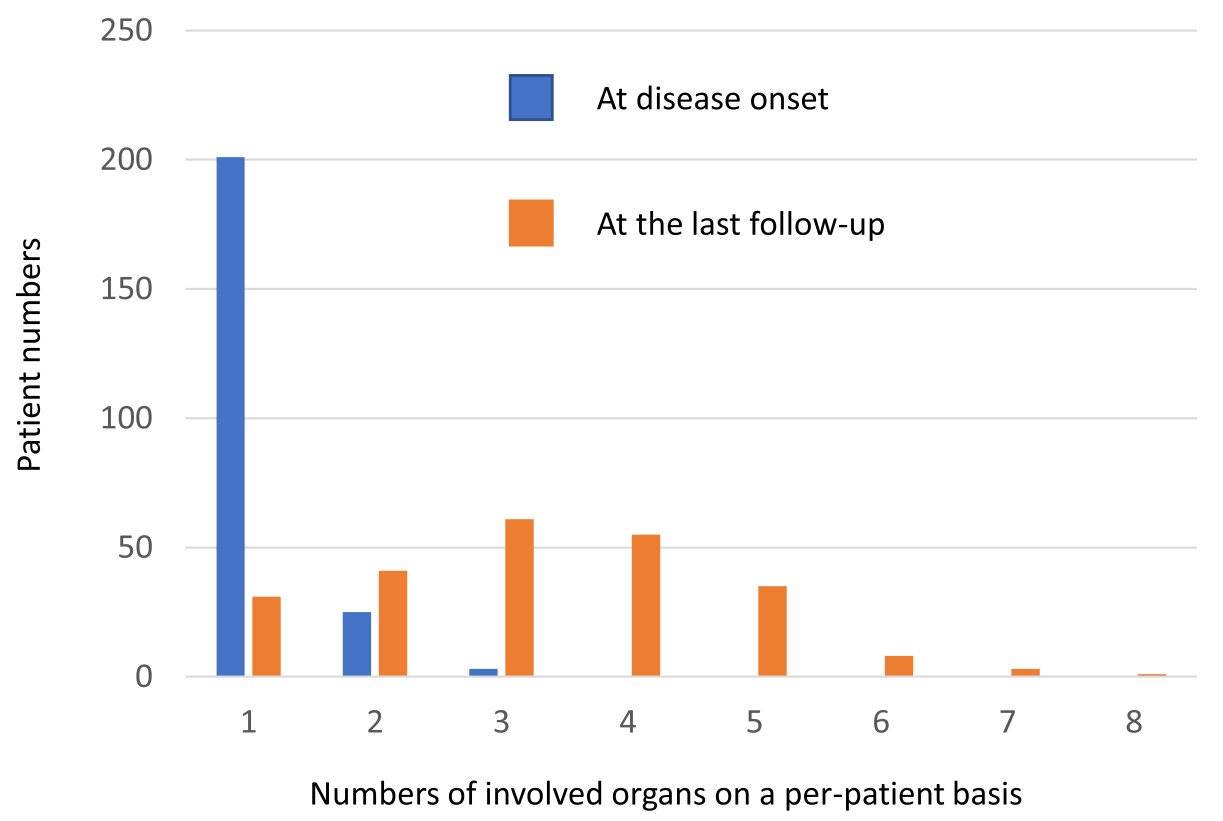

Fig. 1 Involved organ numbers per-patient at disease onset and at the last follow-up in 229 patients with RP. The involved organ numbers perpatient was $1.13 \pm 0.03$ at disease onset. At the onset, 201 patients had single manifestation and 28 patients had multiple manifestations. Cumulative numbers of involved organs at the last follow-up were $3.25 \pm 0.10$. Disease duration from the first symptom to the last follow-up was $4.69 \pm 0.33$ years 


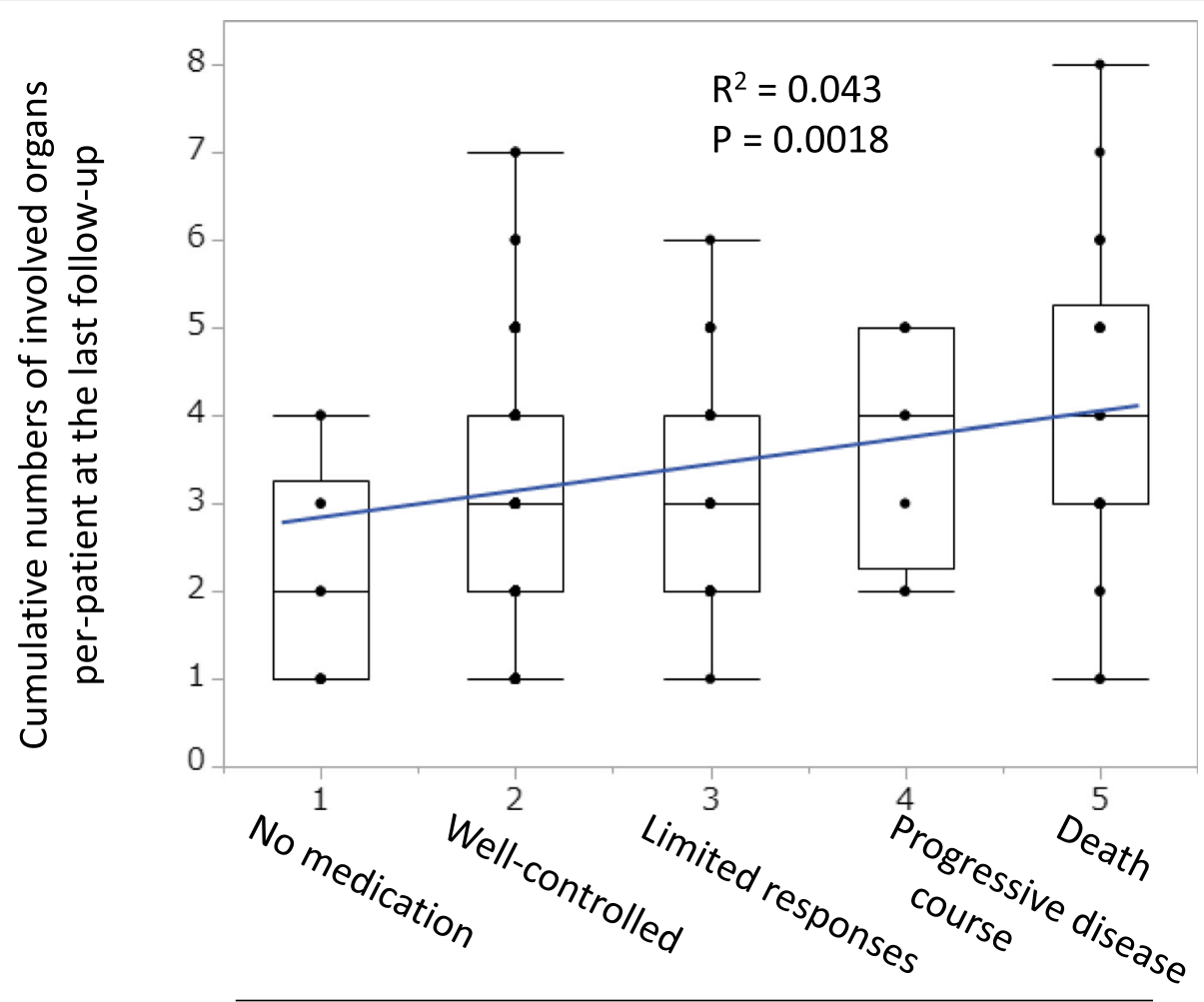

Prognostic stages

Fig. 2 Comparison of cumulative numbers of involved organs per-patient and their prognostic stages. Patient clinical prognosis was assigned into 5 stages, namely 1) no medication, 2) well-controlled, 3) limited responses, 4) progressive disease courses, and 5) death. We assessed the relationship between cumulative numbers of involved organs per-patient and their prognostic stages. We found that the numbers of involved organs per-patient increased along with the prognosis stages. A box plot of each subgroup of RP patients and a regression line were indicated

\section{Evaluation of involved organs at disease onset and at the last follow-up}

We then evaluated organ involvement at disease onset and at the last follow-up in detail.

At the onset, 135 patients had auricular involvement (59\% of 229 patients, auricular-onset subgroup; abbreviated as $\mathrm{AO}$ ) and 48 patients had respiratory involvement (21\%, respiratory-onset; RO). 46 patients presented with other conditions (20\%, miscellaneous-onset; MO), namely ocular involvement (18 patients, 7.9\%), inner ear dysfunction ( 9 patients, 3.9\%), joint involvement (8 patients, $3.5 \%$ ), CNS involvement (6 patients, $2.6 \%$ ), nasal chondritis (3 patients, 1.3\%), and skin involvement (2 patients, $0.87 \%)$. We found no significant differences in gender, age, age at disease onset, and disease duration among AO, RO, and MO subgroups (Table 1). Excluded 4 patients from this study with auricular and respiratory involvement at disease onset had moderate clinical courses (mean age at onset, $58.0 \pm 15.9$ years; disease duration, $6.25 \pm 1.25$ years; prognostic stages, $2.00 \pm 0.00$; cumulative numbers of involved organs, $3.33 \pm 0.28$ organs).
We found no significant differences in the use of immunosuppressants (prednisolone, methotrexate, cyclophosphamide, cyclosporine $\mathrm{A}$, and azathioprine) and biologics (etanercept, adalimumab, and tocilizumab) among the 3 subgroups, except for infliximab. Infliximab was frequently administered in $\mathrm{RO}$ patients $(11.8 \pm$

Table 1 Patient demographic data of $\mathrm{AO}^{\mathrm{a}}$ (Auricular-Onset) subgroup, $\mathrm{RO}^{\mathrm{a}}$ (Respiratory-Onset) subgroup, and $\mathrm{MO}^{\mathrm{a}}$ (Miscellaneous-Onset) subgroup

\begin{tabular}{llll}
\hline & AO group & RO group & MO group \\
\hline Patient number $(\mathrm{n})$ & 135 & 48 & 46 \\
Gender (male-female) & $67: 68$ & $24: 24$ & $28: 18$ \\
Mean age & $56 \pm 1.5^{\mathrm{b}}$ & $57 \pm 2.2$ & $60 \pm 2.2$ \\
Mean age at onset & $52 \pm 1.5$ & $52 \pm 2.2$ & $56 \pm 2.3$ \\
Disease duration, years & $4.9 \pm 0.5$ & $5.3 \pm 0.7$ & $3.6 \pm 0.4$
\end{tabular}

${ }^{a} \mathrm{AO}$ : patients with auricular involvement at disease onset (Auricular-Onset), RO: patients with respiratory involvement at disease onset (Respiratory-Onset), MO: patients with miscellaneous organ involvement at disease onset (Miscellaneous-Onset). 4 patients with both respiratory and auricular involvement at disease onset were excluded from this study due to their small numbers, to simplify the analysis. ${ }^{\mathrm{b}} \mathrm{Age}$, age at onset, and disease duration were expressed as mean \pm standard error of the mean 
$0.05 \%)$ compared with $\mathrm{AO}$ patients $(2.18 \pm 0.01 \%)$ and MO subgroup $(0.00 \pm 0.00 \%)$.

At the last follow-up, 117, 47, and 65 patients had auricular involvement (51\% of 229 patients, auricular-the last subgroup; $\mathrm{AL})$, respiratory involvement $(21 \%$, respiratory-the last subgroup; RL), and both respiratory and auricular involvement (28\%, both-the last subgroup; BL), respectively.

Patients involved in this study demonstrated either respiratory involvement, auricular involvement, or both involvement at the last follow-up without exception. 199 patients (87\%) had extra-respiratory and extra-auricular conditions at the last follow-up as we previously reported [6, 13-15].

We evaluated the incidence of extra-auricular and extra-respiratory manifestations at the last follow-up based on the subgroup analysis at the onset (Table 2). The incidence of ocular and inner ear involvement were significantly higher in $\mathrm{MO}$ patients than those in $\mathrm{AO}$ and RO patients (Table 2). The incidence of CNS and cardiovascular involvement were significantly higher in MO patients than those in RO patients (Table 2).

27 of 28 RP patients with CNS involvement (96\% of 28 patients) were derived from $\mathrm{AO}$ and $\mathrm{MO}$ patients and, at the last follow-up, $25(89 \%)$ and $3(11 \%)$ patients were allocated to AL and BL subgroups, respectively. No RP patients with CNS involvement fell into RL subgroup. In the MO subgroup, 6 patients presented with meningitis/ encephalitis preceding any detectable chondritis and developed auricular chondritis later in the disease course.

\section{Comparison of mortality rates among 3 patient subgroups at disease onset}

Mortality rate was obtained in each of 3 patient subgroups at disease onset. We then calculated the rate in each of 3 patient subgroups at the last follow-up (Table 3).

The mortality rate was $5.9 \%$ in $135 \mathrm{AO}$ patients. In the AO patients, 91 patients (67\% of 135 patients) and 44 (33\%) were allocated into BL and AL subgroups, with $3.3 \%(3 / 91)$ and $11 \%(5 / 44)$ mortality rates, respectively.

The mortality rate was $15 \%$ in $48 \mathrm{RO}$ patients. In the RO patients, 39 patients ( $81 \%$ of 48 patients) and 9 (19\%) were allocated into RL and BL subgroups, with 13 and $22 \%$ mortality rates, respectively.

$46 \mathrm{MO}$ patients showed a high mortality rate (15\%, $7 /$ $46)$ and the mortality rate was significantly higher than AO patients $(P=0.048)$ (Table 3$)$. Their causes of death included encephalitis, myocardial infarction, and a chronic myeloproliferative disorder

We then focused on RP patients without respiratory involvement throughout their courses. To this end, patients of $\mathrm{MO}$ and $\mathrm{AO}$ subgroups who did not have respiratory involvement until the last follow-up (117 patients) were analyzed. Mortality rate was significantly higher in $\mathrm{MO}$ patients (19\%) than that in $\mathrm{AO}$ patients (3.3\%, $P=0.013)$ (Table 3$)$.

We recognized 7 patients with hematologic malignancies and 5 patients with solid malignancies in the 229 patients. They consisted of $6 \mathrm{AO}, 3 \mathrm{RO}$, and $3 \mathrm{MO}$ patients and their mortality rate was $25 \%(3 / 12)$.

\section{Comparison of cumulative numbers of involved organs among the 3 patient subgroups at the onset}

When we compared cumulative numbers of involved organs per-patient among $\mathrm{AO}, \mathrm{RO}$, and $\mathrm{MO}$ patients, the numbers were significantly higher in $\mathrm{MO}$ patients (3.91 \pm 0.18) than those in AO patients $(3.24 \pm 0.13, P=0.032)$ and RO patients $(2.65 \pm 0.21, P<0.001)$ (Fig. 3a). The numbers were significantly higher in $\mathrm{AO}$ patients than those in RO patients $(P=0.030)$. We found that the MO patients were followed thereafter by respiratory involvement and/or auricular involvement without exception (Table 3).

In the analysis of $\mathrm{MO}$ and $\mathrm{AO}$ patients who did not have respiratory involvement until the last follow-up, MO patients had significantly higher cumulative numbers of involved organs per-patient $(3.88 \pm 0.17)$ than AO patients $(2.92 \pm 0.15, P=0.012)$.

\section{Comparison of prognostic stages among the 3 patient subgroups at the onset}

When we compared prognostic stages at the last followup among $\mathrm{AO}, \mathrm{RO}$, and $\mathrm{MO}$ patients, the stage values were significantly larger in RO patients $(2.73 \pm 0.16)$ than those in AO patients $(2.32 \pm 0.08, P=0.035)$ (Fig. 3b), suggesting poorer prognosis of RO patients.

In the analysis of $\mathrm{MO}$ and $\mathrm{AO}$ patients who did not have respiratory involvement until the last follow-up, MO patients showed significantly worse (poorer) prognostic stages $(2.73 \pm 0.23)$ than AO patients $(2.09 \pm 0.07$, $P=0.029$ ).

Collectively, MO patients (even without respiratory involvement throughout) and $\mathrm{RO}$ patients showed relatively poorer prognosis compared with AO patients.

\section{Discussion}

$\mathrm{RP}$ is a remittent and episodic disease and extent of the tissue damage increases with time $[2-4,6,16]$. Mortality rates were reported to increase in patients with respiratory involvement $[2-4,6]$, cardiovascular involvement $[2-4,15]$, CNS involvement [2, 13], and hematological disorders [4]. We found that cumulative numbers of involved organs at the last follow-up associated positively with prognostic stages (Fig. 2). In this study, we suggest that the cumulative numbers of involved organs at the last follow-up, as well as prognostic stages, may be a predictor of disease progression in RP. 


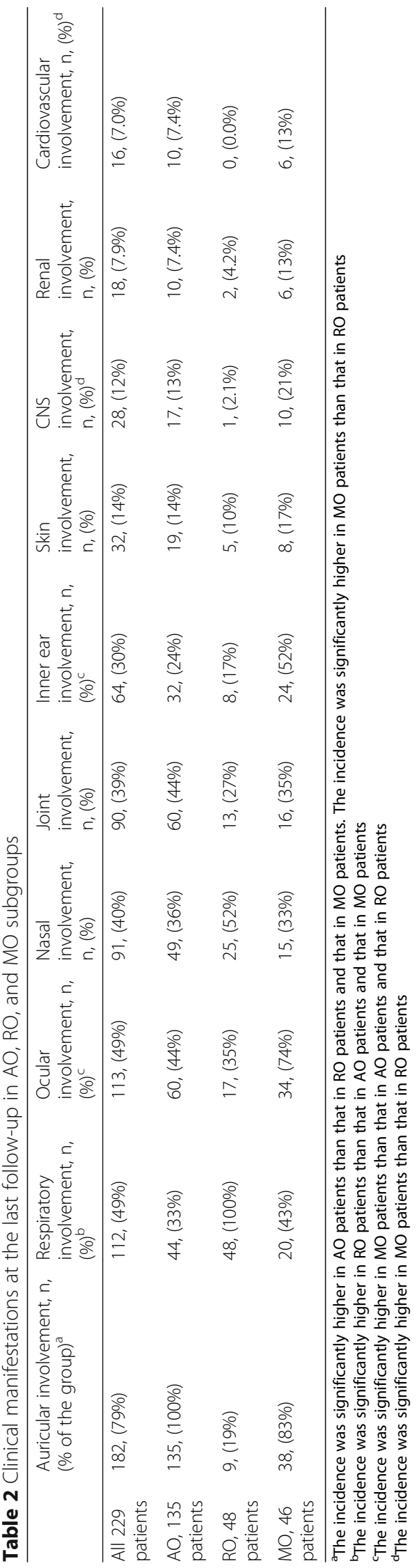


Table 3 Involved organs at disease onset and at the last follow-up, and the mortality rates

\begin{tabular}{|c|c|c|c|}
\hline Onset & Mortality rates (Death) & Last follow-up & Mortality rates (Death) \\
\hline \multirow[t]{2}{*}{ AO, 135 patients } & $5.9 \%(8)^{\mathrm{a}}$ & $\mathrm{AL}^{\mathrm{b}}, 91$ patients & $3.3 \%(3)$ \\
\hline & & $\mathrm{BL}^{\mathrm{b}}, 44$ patients & $11 \%(5)$ \\
\hline \multirow[t]{2}{*}{ RO, 48 patients } & $15 \%(7)$ & RL, 39 patients & $13 \%(5)$ \\
\hline & & $\mathrm{BL}^{\mathrm{b}}, 9$ patients & $22 \%(2)$ \\
\hline \multirow[t]{3}{*}{ MO, 46 patients } & $15 \%(7)^{\mathrm{a}}$ & AL, 26 patients & $19 \%(5)$ \\
\hline & & RL, 8 patients & $0 \%(0)$ \\
\hline & & $\mathrm{BL}, 12$ patients & $17 \%(2)$ \\
\hline
\end{tabular}

${ }^{\mathrm{a}}$ Mortality rate was significantly higher in $\mathrm{MO}$ patients than that in $\mathrm{AO}$ patients $(\mathrm{P}=0.048) .{ }^{\mathrm{b}} \mathrm{AL}$ : patients with auricular without respiratory involvement at the last follow-up (Auricular-Last), RL: patients with respiratory without auricular involvement at the last follow-up (Respiratory-Last), BL: patients with both respiratory and auricular involvement at the last follow-up (Both-Last). MO patients demonstrated poor prognosis even without respiratory involvement, namely $26 \mathrm{MO}-\mathrm{AL}$ patients, at the last follow-up

We found that the overall prognosis of $\mathrm{RO}$ patients was poorer than that of AO patients (Fig. 3b). Recently, it has been proposed that patients with respiratory involvement were distinctive from other RP patients in view of their clinical characteristics, responses to the treatment, and the prognosis [17]. Our current finding supports this proposal.

We observed that the cumulative numbers of involved organs at the last follow-up were higher in MO patients than those in AO patients and RO patients (Fig. 3a). Actually, $46 \mathrm{MO}$ patients were allocated into AL (Auricular-Last) subgroup (54\%, 25 of 46 patients), RL (Respiratory-Last) subgroup (17\%, 8 patients), and BL (Both-Last) subgroup (28\%, 13 patients) (Table 3). The incidence of ocular and inner ear involvement were significantly higher in $\mathrm{MO}$ patients than that in $\mathrm{AO}$ and
RO patients (Table 2). The incidence of CNS and cardiovascular involvement were significantly higher in $\mathrm{MO}$ patients than that in RO patients (Table 2).

The MO patients showed a significantly higher mortality rate $(15 \%)$ than AO patients (5.9\%) (Table 3). Previous studies demonstrated that miscellaneous-onset RP patients were identified with CNS involvement [18] and skin involvement $[19,20]$ at the onset, both of which were suggested to associate with severe complications [18-20]. Miscellaneous disorders without chondritis may be challenging to diagnose in patients with RP. Absence of ear and nasal involvement was reported to lead to the diagnostic delay [21].

We found that $12 \%$ (28 patients) of 229 patients with RP developed CNS involvement. 6 patients (21\% of 28 patients) with CNS involvement at disease onset
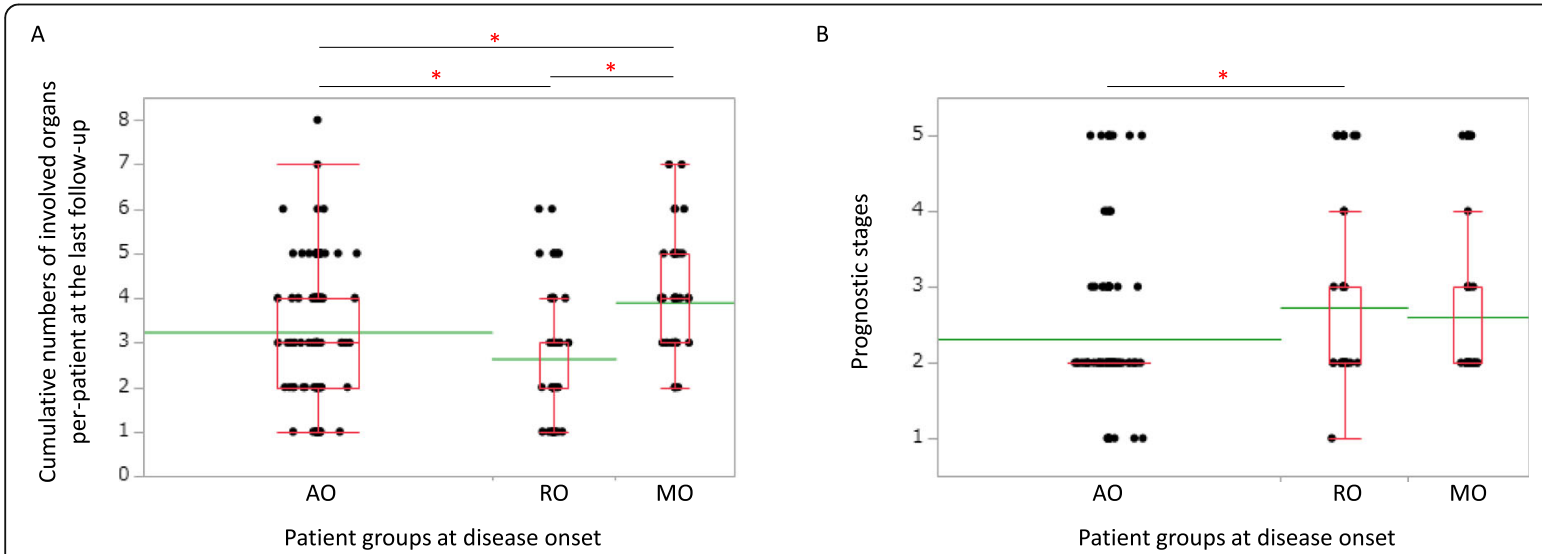

$* P<0.05$

Fig. 3 Comparison of involved organ numbers and prognostic stages among 3 patient subgroups at disease onset. We compared cumulative numbers of involved organs per-patient at the last follow-up (a) and prognostic stages at the last follow-up (b) among 3 patient subgroups initially assigned at disease onset; $\mathrm{AO}, \mathrm{RO}$, and $\mathrm{MO}$ subgroups. a When we compared cumulative numbers of involved organs per-patient at the last follow-up among $\mathrm{AO}, \mathrm{RO}$, and $\mathrm{MO}$ patients, the numbers were significantly higher in $\mathrm{MO}$ patients than those in $\mathrm{AO}$ patients and RO patients. The numbers were significantly higher in $\mathrm{AO}$ patients than those in $\mathrm{RO}$ patients. We found that the $\mathrm{MO}$ patients were followed thereafter by respiratory involvement and/or auricular involvement without exception (Table 3).b When we compared prognostic stages at the last follow-up among $\mathrm{AO}, \mathrm{RO}$, and $\mathrm{MO}$ patients, the stage values were significantly larger in $\mathrm{RO}$ patients than those in $\mathrm{AO}$ patients. $\mathrm{A}$ box plot (red line) and a mean level (green line) of each subgroup of RP patients were indicated 
Table 4 Relationships between meningitis/encephalitis and chondritis in RP patients based on a review of the literature

\begin{tabular}{|c|c|c|c|c|c|c|c|c|c|c|}
\hline & \multirow{2}{*}{$\begin{array}{l}\text { Mean } \\
\text { age at } \\
\text { onset (y) }\end{array}$} & \multirow{2}{*}{$\begin{array}{l}\text { Male } \\
\text { to } \\
\text { female } \\
\text { ratio }\end{array}$} & \multirow{2}{*}{$\begin{array}{l}\text { Time } \\
\text { interval }^{\mathbf{b}} \\
\text { (months) }^{\text {mons }}\end{array}$} & \multirow{2}{*}{$\begin{array}{l}\text { Follow- } \\
\text { up } \\
\text { (months) }\end{array}$} & \multicolumn{3}{|c|}{ Onset } & \multicolumn{3}{|c|}{$\begin{array}{l}\text { Last } \\
\text { follow-up }\end{array}$} \\
\hline & & & & & $\mathrm{AO}$ & $\mathrm{RO}$ & $\mathrm{MO}$ & $\mathrm{AL}$ & $R L$ & $B L$ \\
\hline All patients $(n=50)$ & $56 \pm 1.5^{d}$ & $3.2: 1$ & $N A^{e}$ & $13 \pm 2.0$ & 34 & 4 & 22 & 41 & 0 & 9 \\
\hline $\begin{array}{l}\text { Patients presented with meningitis/encephalitis and developed chondritis later } \\
(n=14)\end{array}$ & $57 \pm 3.1$ & $3.7: 1$ & $6.2 \pm 1.6$ & $8.5 \pm 2.1$ & 0 & 0 & 3 & 13 & 0 & 1 \\
\hline $\begin{array}{l}\text { Patients presented with chondritis and developed meningitis/encephalitis later } \\
(n=17)\end{array}$ & $58 \pm 2.3$ & $7.5: 1$ & $12 \pm 4.3$ & $18 \pm 4.3$ & 16 & 1 & 7 & 14 & 0 & 3 \\
\hline Patients presented with both meningitis/encephalitis and chondritis $(n=19)$ & $55 \pm 2.4$ & $1.7: 1$ & NA & $11 \pm 3.5$ & 18 & 3 & 12 & 14 & 0 & 5 \\
\hline
\end{tabular}

${ }^{\mathrm{a}} \mathrm{A}$ review of the literature was conducted on RP meningitis/encephalitis using PubMed [18, 22-42]

${ }^{\mathrm{b}}$ Time interval (months) between the onset of meningitis/encephalitis and that of chondritis

${ }^{c}$ Follow-up duration of patients (months)

${ }^{\mathrm{d}}$ Age, time interval, and follow-up duration were expressed as mean \pm standard error of the mean

eNA, Not applicable

presented with meningitis/encephalitis preceding any detectable chondritis and developed auricular chondritis later in the disease course. In the 28 patients, 25 (89\%) and $3(11 \%)$ patients with CNS involvement were allocated to AL and BL subgroups at the last follow-up, respectively, and no patients fell into RL subgroup. Again, CNS involvement and respiratory involvement looked mutually exclusive [7].

It was reported that CNS involvement occurred in 8$12 \%$ of RP patients $[2,4,13,16]$ and the mortality rates were high $[13,18,22,23]$. When we reviewed the literature [18, 22-42], 14 of $50 \mathrm{RP}$ patients $(28 \%)$ with meningitis/encephalitis developed neurological symptoms preceding any detectable chondritis (Table 4). At the last follow-up, 82 and $18 \%$ of the patients with CNS involvement were allocated to AL and BL subgroups, respectively (Table 4), consistent with our finding of close relationship between auricular involvement and CNS involvement [8].

Our findings support the notion that RP patients with respiratory involvement relate to poorer prognosis $[2,3$, $6,17]$. It has been generally accepted that early detection of and treatment on respiratory involvement are important to reducing mortality rate of RP [17].

This study has a limitation because of its retrospective study design. We obtained the clinical data at disease onset and at the last follow-up. Further studies are needed to elucidate the pathological consequence of inflammation of patients with RP, especially focusing on the insidious disease progression.

\section{Conclusions}

When we analyzed clinical information of $229 \mathrm{RP}$ patients with a focus on the disease onset, mortality rates were worse in RO (Respiratory-Onset) patients and MO (Miscellaneous-Onset) patients than AO (Auricular-Onset) patients. When we analyzed the data in 117 patients without respiratory involvement throughout their disease course, MO patients showed poorer prognosis than
AO patients. These findings suggest that $\mathrm{MO}$ patients were considered to be exposed to high-risk of disease progression with poorer prognosis.

\section{Abbreviations}

AL: Patients with auricular involvement at the last follow-up; AO: Patients with auricular involvement at disease onset; BL: Patients with both respiratory and auricular involvement at the last follow-up; CNS: Central nervous system; MO: Patients with miscellaneous organ involvement at disease onset; RL: Patients with respiratory involvement at the last follow-up; RO: Patients with respiratory involvement at disease onset; RP: Relapsing polychondritis

\section{Acknowledgements}

The authors wish to thank Professor Kenji Takai of Department of Immunology and Medicine, St. Marianna University School of Medicine for his statistical assistance, and Relapsing Polychondritis Associations of Japan (HORP) for their assistance in the performance of this study.

\section{Authors' contributions}

JS data collection, study conception, study design, analysis, writing (draft), YY data collection, study design, analysis, writing (review and editing), KK data collection, study design, writing (review and editing), NS data collection, study conception, study design, analysis, writing (review and editing). All authors read and approved the final manuscript.

\section{Funding}

This work was supported in part by Grants-in-Aid from the Research Committee of Rare Disease, the Ministry of Health, Labor and Welfare of Japan.

\section{Availability of data and materials}

The datasets used and/or analyzed during the current study are available from the corresponding author on reasonable request.

\section{Ethics approval and consent to participate}

This study was approved by the institutional review boards of St. Marianna University School of Medicine (approval number 2406) and was registered with the University Hospital Medical Information Network-Clinical Trials Registry (UMIN000018937). We used an anonymous physician questionnaire for the survey [6] and informed consent was not required in Japan at that time (2009), and even now [43].

\section{Consent for publication}

Not applicable (anonymous data).

\section{Competing interests}

The authors declare that they have no competing interests. 
Received: 5 February 2020 Accepted: 19 May 2020

Published online: 11 September 2020

\section{References}

1. Letko E, Zafirakis P, Baltatzis S, Voudouri A, Livir-Rallatos C, Foster CS. Relapsing polychondritis: a clinical review. Semin Arthritis Rheum. 2002;31: 384-95

2. McAdam LP, O'Hanlan MA, Bluestone R, Pearson CM. Relapsing polychondritis: prospective study of 23 patients and a review of the literature. Medicine (Baltimore). 1976;55:193-215.

3. Michet CJ Jr, McKenna CH, Luthra HS, O'Fallon WM. Relapsing polychondritis. Survival and predictive role of early disease manifestations. Ann Intern Med. 1986;104:74-8.

4. Dion J, Costedoat-Chalumeau N, Sène D, Cohen-Bittan J, Leroux G, Dion C, et al. Relapsing polychondritis can be characterized by three different clinical phenotypes: analysis of a recent series of 142 patients. Arthritis Rheumatol. 2016;68:2992-3001.

5. Castañeda S, Vicente EF, González-Gay MA. Positron emission tomography/ computed tomography in relapsing polychondritis. Rheumatology. 2020;59:7-8.

6. Oka H, Yamano Y, Shimizu J, Yudoh K, Suzuki N. A large-scale survey of patients with relapsing polychondritis in Japan. Inflamm Regen. 2014;34: 149-56.

7. Shimizu J, Yamano Y, Yudoh K, Suzuki N. Organ involvement pattern suggests subgroups within relapsing polychondritis: comment on the article by Dion et al. Arthritis Rheumatol. 2018;70:148-9.

8. Shimizu J, Yamano Y, Kawahata K, Suzuki N. Relapsing polychondritis patients were divided into three subgroups: patients with respiratory involvement ( $R$ subgroup), patients with auricular involvement ( $A$ subgroup), and overlapping patients with both involvements ( $\mathrm{s}$ subgroup), and each group had distinctive clinical characteristics. Medicine. 2018;97: e12837

9. Polman $\mathrm{CH}$, Reingold SC, Banwell B, Clanet M, Cohen JA, Filippi M, et al. Diagnostic criteria for multiple sclerosis: 2010 revisions to the McDonald criteria. Ann Neurol. 2011;69:292-302.

10. Winters R, Winters A, Amedee RG. Statistics: a brief overview. Ochsner J. 2010;10:213-6.

11. McHugh ML. The Chi-Square test of Independence. Biochem Med (Zagreb). 2013;23:143-9.

12. Hamada C. Statistical analysis for toxicity studies. J Toxicol Pathol. 2018;31: 15-22.

13. Suzuki N, Shimizu J, Oka H, Yamano Y, Yudoh K. Neurological involvement of relapsing polychondritis in Japan: an epidemiological study. Inflamm Regen. 2014;34:206-8.

14. Shimizu J, Oka H, Yamano Y, Yudoh K, Suzuki N. Cutaneous manifestations of patients with relapsing polychondritis: an association with extracutaneous complications. Clin Rheumatol. 2016;35:781-3.

15. Shimizu J, Oka H, Yamano Y, Yudoh K, Suzuki N. Cardiac involvement in relapsing polychondritis in Japan. Rheumatology (Oxford). 2016;55:583-4.

16. Zeuner M, Straub RH, Rauh G, Albert ED, Schölmerich J, Lang B. Relapsing polychondritis: clinical and immunogenetic analysis of 62 patients. J Rheumatol. 1997;24:96-101.

17. de Montmollin N, Dusser D, Lorut C, Dion J, Costedoat-Chalumeau N, Mouthon $\mathrm{L}$, et al. Tracheobronchial involvement of relapsing polychondritis. Autoimmun Rev. 2019;18:102353.

18. Wang ZJ, Pu CQ, Wang ZJ, Zhang JT, Wang XQ, Yu SY, et al. Meningoencephalitis or meningitis in relapsing polychondritis: four case reports and a literature review. J Clin Neurosci. 2011;18:1608-15.

19. Francès C, el Rassi R, Laporte JL, Rybojad M, Papo T, Piette JC. Dermatologic manifestations of relapsing polychondritis. A study of 200 cases at a single center. Medicine (Baltimore). 2001;80:173-9.

20. Tronquoy AF, de Quatrebarbes J, Picard D, Courville P, Balguerie X, Boullie MC, et al. Papular and annular fixed urticarial eruption: a characteristic skin manifestation in patients with relapsing polychondritis. J Am Acad Dermatol. 2011;65:1161-6.

21. Ferrada MA, Grayson PC, Banerjee S, Sikora KA, Colbert RA, Sinaii N, et al Patient perception of disease-related symptoms and complications in relapsing polychondritis. Arthritis Care Res. 2018;70:1124-31.

22. Nara M, Komatsuda A, Togashi M, Wakui H. Relapsing polychondritis with encephalitis: a case report and literature review. Intern Med. 2015;54:231-4.
23. Ellis RJ, Mbizvo GK, Jacob A, Doran M, Larner AJ. Relapsing polychondritis complicated by cognitive dysfunction: two distinct clinical phenotypes? Int J Neurosci. 2017;127:124-34.

24. Almackenzie M, Alharbi A, Alhassan S, Cook E, Altorok N. Successful treatment of central nervous system vasculitis associated with relapsing polychondritis with cyclophosphamide. Am J Med Sci. 2017:353:495-7.

25. Stewart SS, Ashizawa T, Dudley AW Jr, Goldberg JW, Lidsky MD. Cerebral vasculitis in relapsing polychondritis. Neurology. 1988;38:150-2.

26. Kothare SV, Chu CC, VanLandingham K, Richards KC, Hosford DA, Radtke RA Migratory leptomeningeal inflammation with relapsing polychondritis. Neurology. 1998:51:614-7.

27. Fujiki F, Tsuboi Y, Hashimoto K, Nakajima M, Yamada T. Non-herpetic limbic encephalitis associated with relapsing polychondritis. J Neurol Neurosurg Psychiatry. 2004;75:1646-7.

28. Yan M, Cooper W, Harper C, Schwartz R. Dementia in a patient with nonparaneoplastic limbic encephalitis associated with relapsing polychondritis. Pathology. 2006;38:596-9.

29. Cañas CA, Díaz-Martínez JC, Tobón GJ. Combination of hypertrophic pachymeningitis, PR3-ANCA-positive vasculitis, and relapsing polychondritis. I Rheumatol. 2011;38:966-7.

30. Storey K, Matěj R, Rusina R. Unusual association of seronegative, nonparaneoplastic limbic encephalitis and relapsing polychondritis in a patient with history of thymectomy for myasthenia: a case study. J Neurol. 2011;258:159-61.

31. Niwa A, Okamoto Y, Kondo T, Nabatame H, Takahashi R, Tomimoto H. Perivasculitic panencephalitis with relapsing polychondritis: an autopsy case report and review of previous cases. Intern Med. 2014;53:1191-5.

32. Hatti K, Giuliano V. Central nervous system involvement in relapsing polychondritis. J Clin Rheumatol. 2014;20:396-7.

33. Hwang YP, Kuo R, Chen TL, Chen PH, Cheng SJ. Relapsing polychondritis presenting with meningoencephalitis and dementia: correlation with neuroimaging and clinical features. Acta Neurol Taiwanica. 2015;24:30-3.

34. Baba T, Kanno S, Shijo T, Nishio Y, lizuka O, Kamimura N, et al. Callosal disconnection syndrome associated with relapsing polychondritis. Intern Med. 2016:55:1191-3.

35. Jeon $\mathrm{CH}$. Relapsing polychondritis with central nervous system involvement: experience of three different cases in a single center. J Korean Med Sci. 2016;31:1846-50.

36. Simabukuro MM, Lucato LT, Shinjo SK, Flores WL, Castro LH. Teaching Neurolmages: limbic encephalitis associated with relapsing polychondritis. Neurology. 2016;86:e215-6.

37. Tsai M, Hu M, Zussman J, Worswick S. Relapsing polychondritis with meningoencephalitis. Cutis. 2017;99:43-6.

38. Ahn SW, Park MS, Jeong HB, Kwon OS, Yoon BN, Kim HS, et al. Relapsing polychondritis presented with encephalitis followed by brain atrophy. Exp Neurobiol. 2017:26:66-9.

39. Ducci RD, Germiniani FMB, Czecko LEA, Paiva ES, Teive HAG. Relapsing polychondritis and lymphocytic meningitis with varied neurological symptoms. Rev Bras Reumatol Engl Ed. 2017;57:623-5.

40. Cao J, Zhang M. Pleocytosis in a patient with relapsing polychondritis accompanied by meningoencephalitis: a case report. BMC Neurol. 2018;18:53.

41. Zhu Z, Tian D, Ren N, Zhao Z, Wang X, Chen L. Limbic encephalitis with relapsing polychondritis: persistent white matter lesions and brain atrophy. J Int Med Res. 2018;46:5297-302

42. Shen K, Yin G, Yang C, Xie Q. Aseptic meningitis in relapsing polychondritis: a case report and literature review. Clin Rheumatol. 2018;37:251-5.

43. The Ministry of Health, Labor and Welfare of Japan. 2015. Ethical Guidelines for Medical and Health Research Involving Human Subjects. https://www. mhlw.go.jp/file/06-Seisakujouhou-10600000-Daijinkanboukouseikagakuka/ 0000080278.pdf

\section{Publisher's Note}

Springer Nature remains neutral with regard to jurisdictional claims in published maps and institutional affiliations. 